\title{
Benign teratoma of neck in adult: a rare case report
}

\section{Mohammed Humaam Ansari*, Atishkumar Balajirao Gujrathi, Vijayalaxmi Ambulgekar}

Department of Otorhinolaryngology, Dr. Shankarrao Chavan Government Medical College, Nanded, Maharashtra, India

Received: 21 July 2017

Accepted: 31 August 2017

\section{*Correspondence: \\ Dr. Mohammed Humaam Ansari, \\ E-mail: humaam91@gmail.com}

Copyright: (c) the author(s), publisher and licensee Medip Academy. This is an open-access article distributed under the terms of the Creative Commons Attribution Non-Commercial License, which permits unrestricted non-commercial use, distribution, and reproduction in any medium, provided the original work is properly cited.

\begin{abstract}
Cervical teratomas are extremely rare germ cell tumours. Cervical teratoma is much more common in newborn than adults, and in contrast to the paediatric cases adult teratomas have been highly malignant. Cervical teratoma incorporates lesions arising in the anterior and posterior triangles of the neck. Cervical teratoma can reach enormous size and cause airway obstruction. Surgery is the primary modality of treatment as malignant transformation occurs. Hereby, we present a case of benign teratoma of neck in adult which was completely misdiagnosed preoperatively due to its rare occurence in adults. Even though cervical teratoma of adult is extremely rare, it should be considered as an important differential diagnosis in patient of midline cystic neck swelling. Preoperative radiological investigations requires high index of suspicion. Complete surgical resection is recommended.
\end{abstract}

Keywords: Benign, Cervical, Teratoma, Thyroid, Adult

\section{INTRODUCTION}

Teratoma is derived from the Greek word "teras" which means monster. Virchow coined this term in 1863. Teratomatous tumours have been described in a variety of sites and organs. They occur most frequently in the ovary and testis, less frequently in the mediastinum and retro peritoneum and rarely in other sites such as the central nervous system, liver, nasal sinuses, thyroid and cervical area. $^{1,2}$ Designation of a tumour as a teratoma requires demonstration of tissue showing characteristics of all the three germ layers. The degree of immaturity of the tissue determines the malignant potential of the lesion.

Cervical teratoma is very rarely encountered. Cervical teratoma is much more common in newborns than adults and in contrast to the paediatric cases adult teratomas are highly malignant.

Cervical teratoma can reach enormous size and cause airway obstruction. The symptoms are mostly attributed to the mass effect of these lesions. The specific symptoms associated with cervical teratomas vary depending upon the size of the tumour. Small tumours may not cause any symptoms. However, a large teratoma may cause disfigurement and compress nearby structures such as the trachea and oesophagus. ${ }^{3}$

\section{CASE REPORT}

A 24 year old male patient presented with swelling on anterior aspect of neck since 3 months which was progressively increasing in size. There was no history of pain in swelling, fever, trauma, hoarseness of voice, dysphagia, dyspnoea, tremors and palpitations. There was no previous history of thyroid disease in the patient and his family.

Physical examination revealed a palpable mass of approximate size $5 \times 4 \mathrm{cms}$ on left side of anterior aspect of neck near suprasternal region, which was soft in consistency, non-tender and non-fluctuant in nature. There was evidence of movement of swelling on deglutition. Overlying skin was found to be normal. Signs of inflammation were absent. There were no palpable 
cervical lymph nodes. Systemic examination was unremarkable.

\section{Investigations}

Haemogram, chest X-ray and blood chemistries were within normal limits. Thyroid studies revealed a normal T3 and T4 levels. Ultrasound of neck revealed walled, anechoic midline cystic lesion of size $45 \times 36.9 \mathrm{~mm}^{2}$ near suprasternal region. Bilateral thyroid gland appeared to be normal in size shape and echogenicity. Bilateral submandibular glands, parotid glands, carotid arteries appeared normal (Figure 1).

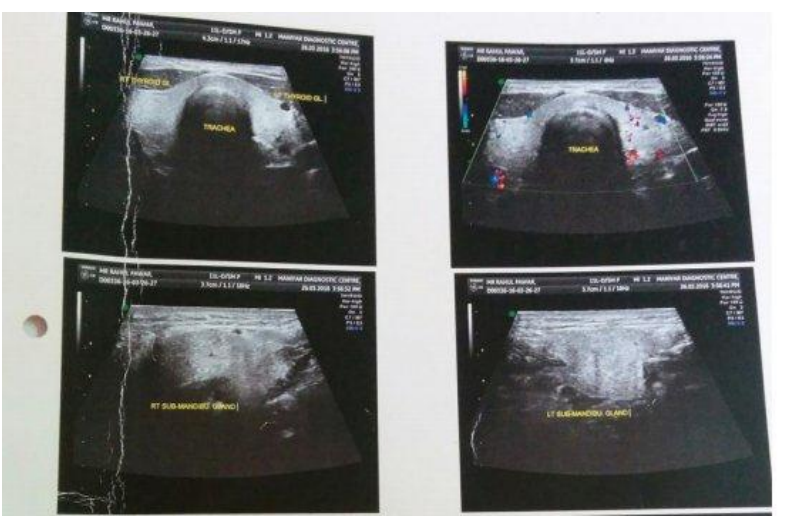

Figure 1: Ultrasonography of neck (USG) revealed walled, anechoic midline cystic lesion of size $45 \times 36.9$ $\mathrm{mm}^{2}$ near suprasternal region.

\section{Fine needle aspiration cytology (FNAC)}

FNAC of the swelling was performed. Cytological examination showed plenty of anucleated and nucleated squamous epithelial cells, plenty of polymorphs and cyst macrophages on a background with granular eosinophilic material. Thyroid follicular epithelial cells were not seen in the smear. A diagnosis suggestive of brachial cyst was given on FNAC.

\section{Procedure}

Patient was planned for excision of cervical mass. The patient underwent surgery under general anaesthesia with orotracheal intubation. Incision was taken over the anterior aspect of neck extending from anterior border of one sternocleidomastoid to another. Subplatysmal flap elevated. After dissecting the fibres of strap muscles, a yellowish white mass was discovered. Mass was lying below thyroid gland, in the supra-sternal region and was separated from the gland. Thyroid gland was found to be normal. The mass was completely removed in toto as the adjacent structures were not infiltrated. Left recurrent laryngeal nerve was identified and preserved. Patient was discharged later on postoperative day 7 without any particular complaints. Uneventful recovery followed. Clinical follow up of the patient has demonstrated no recurrence so far.

\section{Gross examination}

The excised mass was yellowish white, $3 \times 4 \mathrm{cms}$ in size, soft and cystic. At places, it was firm and congested. On cut section serous pale brownish fluid oozed out. At one place the cyst wall was thickened and firm in consistency (Figure 2).
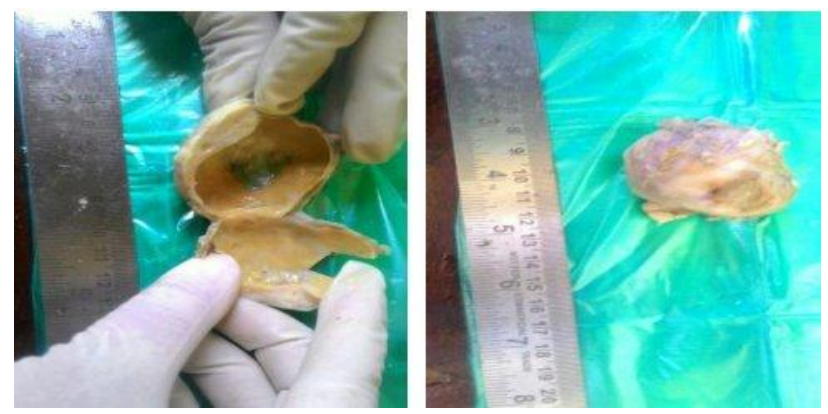

Figure 2: Externally shows a yellow white mass with areas of congestion. On c/s- cystic cavity noted and at one place the cyst wall is thickened.

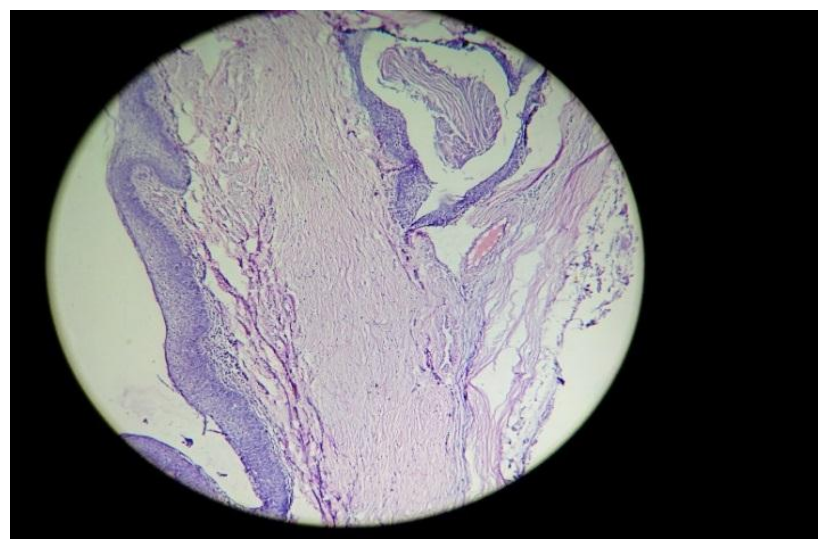

Figure 3: Low power view showing lining stratified squamous epithelium.

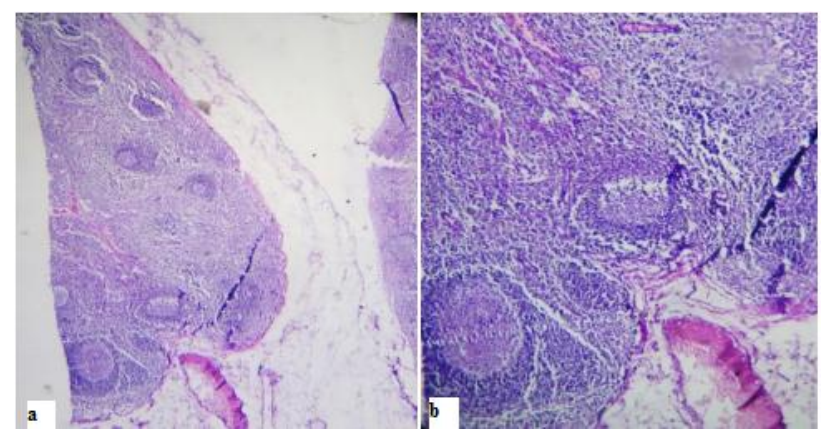

Figure 4: (a \& b) Low power and high power view showing presence of mucin secreting columnar cells and prominent lymphoid follicles.

\section{Histological examination}

Histology revealed stratified squamous epithelium (Figure 3) and pilosebaceous structures, lymphoid tissue 
with prominent lymphoid follicles (Figures 4a and 4b ), fibrocollagenous, mature adipose tissue and mature cartilage (Figures 5a and 5b), ciliated pseudostratified columnar respiratory epithelium (Figure 6) and intestinal columnar epithelium with goblet cells.

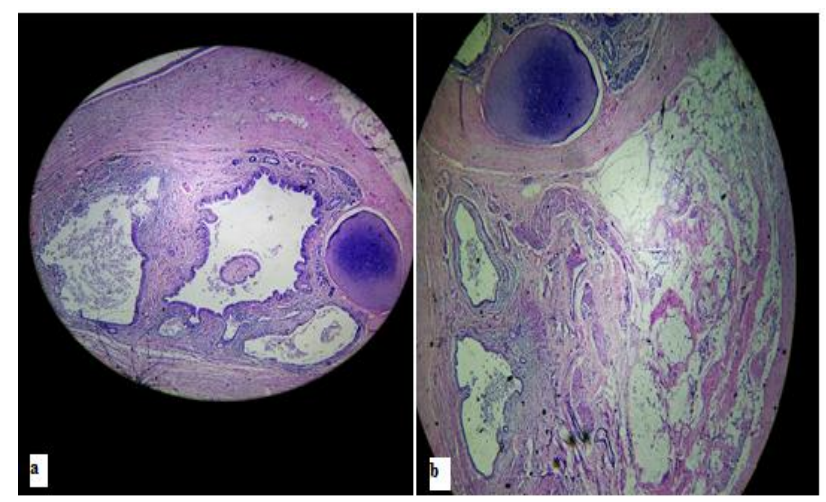

Figure 5: (a \& b) Low power view showing mature cartilage, adipose tissue along with fibrocollagenous tissue.

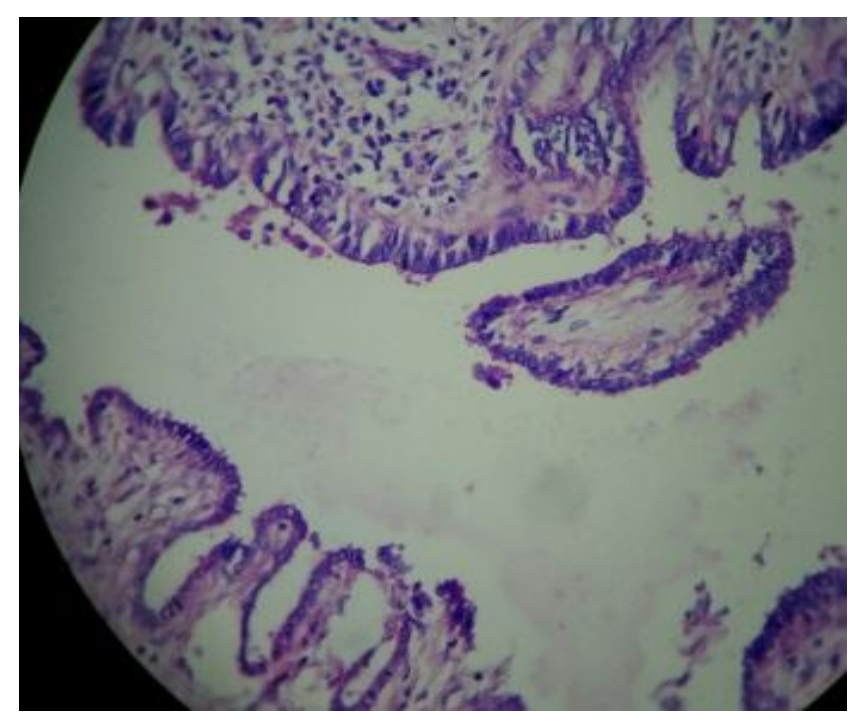

Figure 6: Low power view showing presence of pseudostratified ciliated columnar respiratory epithelium.

\section{DISCUSSION}

Teratomas are embryonal neoplasms that arise when totipotent germ cells escape the developmental control of primary organizers and give rise to tumours containing tissue derived from all three blastodermic layers i.e. ectoderm, endoderm and mesoderm. ${ }^{4}$ The germinal cells migrate from the vitelline sac during the first week of the intrauterine life and colonize the sexual cordon forming primitive undifferentiated gonads. During this migration they arrest and form a germinal tumour. ${ }^{5}$ The first proved case of teratoma of the neck was published by Hess in 1854 , and was restudied microscopically by Wetzel in $1895 .^{6}$
Cervical teratomas are rare tumours with a frequency of $1 / 40000$ birth. Cervical teratoma incorporates lesions arising in the anterior and posterior triangles of neck. ${ }^{1}$ It comprises only about $3 \%$ of all teratomas. They predominate in females ( $75 \%$ of the cases). ${ }^{4}$ The reported incidence of cervical teratoma in newborn, children aged 1 month to 18 years and adults were $75.1 \%, 14.3 \%$ and $10.6 \%$ respectively. ${ }^{1}$

Cervical teratomas are divided into thyroid teratomas and extrathyroid teratomas depending on where they originated. ${ }^{2}$ For the diagnosis of primary thyroid teratoma one of three conditions must be met, 1) a tumour must occupy a portion of the thyroid gland, 2) a direct connection must exist between the tumour and the thyroid, and 3) a teratoma is accompanied by the absence of the thyroid. ${ }^{6}$ Some researchers have made an attempt to classify these tumours on the basis of their relationship to the thyroid gland. It is still debated and stirs controversy among researchers whether teratomas of the thyroid gland and teratoma of a neck origin are distinctively different entities. ${ }^{1}$ However, most cervical teratomas have some type of relationship with the thyroid and the clinical picture and prognosis between these tumours is the same. Therefore many researchers have abandoned separating these tumours and classify all neck teratomas as cervical teratomas. ${ }^{3}$

Radiologically, the diagnosis is supported by ultrasonography, computed tomography or magnetic resonance imaging. Malignant transformation of cervical teratoma has been reported. Complete surgical removal is the elective treatment. ${ }^{7}$ Adjuvant radiotherapy or chemotherapy is generally considered ineffective. ${ }^{4}$

The differential diagnosis of cervical teratoma is metastasis from thyroid carcinoma, cystic squamous cell carcinoma of cervical lymph node arising in the oro/ nasopharynx, follicular adenomas of the thyroid, lymphangiomas, and bronchial cysts. ${ }^{4}$

Surgical removal of a cervical teratoma may involve the removal of a portion of or the entire thyroid gland. In such cases, affected individuals must go on hormone replacement therapy to obtain the hormones normally produced by the thyroid. ${ }^{3}$ Infants with a benign cervical teratoma rarely experience recurrence of the tumour. Malignant cervical teratomas such as those found in adults recur more often. Affected individuals must be monitored periodically to check for recurrence.

\section{CONCLUSION}

Even though cervical teratoma of adult is extremely rare, it should be considered as an important differential diagnosis in patient of midline cystic neck swelling. Preoperative radiological investigations requires high index of suspicion. Complete surgical resection is recommended. 
Funding: No funding sources

Conflict of interest: None declared

Ethical approval: Not required

\section{REFERENCES}

1. Siow SL, Mahendran HA. Cervical Teratoma: A Rare Neck Swelling in an Adult. Am J Med Case Rep. 2015;3(3):75-8.

2. Oak CY, Kim HK, Yoon TM, Lim SC, Park HB, Park HC, et al. Benign Teratoma of the Thyroid Gland. Endocrinol Metab. 2013;28(2):144-8.

3. Adzick NS, Koop CE. Cervical Teratoma. NORD (National Organization for Rare Disorders). 2007. Available from: https://rarediseases.org/rarediseases /cervical-teratoma. Accessed on 10 January 2017.

4. Alimehmeti M, Alimehmeti R, Ikonomi M, Saraci M, Petrela M. Cystic benign teratoma of the neck in adult. World J Clin Cases. 2013;1(6):202-4.
5. Shine NP, Sader C, Gollow I, Lannigan FJ. Congenital cervical teratomas: diagnostic, management and postoperative variability. Auris Nasus Larynx. 2006;33:107-11.

6. Saphir O. Teratoma of the Neck. American J Pathol. 1929;5(3):313-22.

7. Muttillo IA, Maceli F, Giacovazzo F, Luzzatto L, Ruzzetti R, Cortese F, et al. Cervico-mediastinal teratoma. A case report and review of the literature. Ann Ital Chir. 2006;77:335-9.

Cite this article as: Ansari $\mathrm{MH}$, Gujrathi $\mathrm{AB}$, Ambulgekar V. Benign teratoma of neck in adult: a rare case report. Int J Otorhinolaryngol Head Neck Surg 2017;3:1136-9. 